\title{
O DESENVOLVIMENTO DE UMA METACONSCIÊNCIA, NO PROFESSOR, ACERCA DA IMPORTÂNCIA DE VIVENCIAR A LINGUAGEM COMO PRÁTICA SOCIAL NA SALA DE AULA DE LÍNGUA INGLESA POR MEIO DA PESQUISA COLABORATIVA*
}

\author{
Luciane Kirchhof Ticks**
}

Resumo: Neste artigo, discutimos o processo reflexivo vivenciado por duas professoras de inglês ao problematizarem suas ações em sala de aula. Destacamos particularmente o processo de reconfiguração de suas atividades pedagógicas que inicialmente focalizam estruturas lexicogramaticais isoladas e, no decorrer do processo reflexivo, são reconfiguradas em direção ao uso de gêneros textuais e à (des)construção dos contextos de situação e cultura nos quais esses textos são socialmente produridos e vivenciados (MOTTA-ROTH, 2006). Essas reflexões foram desenvolvidas por meio de um processo de pesquisa colaborativo (MAGALHÃES, 2004). A análise do discurso dessas professoras indica que o processo reflexivo thes permitiu desenvolver uma metaconsciência acerca de como a linguagem se organiza e se constitui ao mediar a atividade social.

Palavras-chave: Pesquisa Colaborativa. Análise Crítica do Discurso. Linguagem como Prática Social.

\section{INTRODUÇÃO}

O processo formativo pré-serviço e em serviço, configurado a partir de uma perspectiva reflexiva, tem sido problematizado por diferentes pesquisadores brasileiros (MAGALHÃES; FIDALGO, 2008; GIMENEZ, 2007, 2002; CASTRO, 2006, 2003; entre outros). Para Celani e Magalhães (2002, p. 323), esse enfoque reflexivo significa

\footnotetext{
* Este trabalho discute dados gerados na pesquisa de doutorado desenvolvida pela autora no Programa de Pós-Graduação da Universidade Federal de Santa Maria (UFSM), sob a orientação da Profa. Dra. Désirée Motta-Roth.

** Doutora em Letras pela Universidade Federal de Santa Maria (UFSM); UFSM/CAPES/LabLer; E-mail: <luticks@terra.com.br>.
} 
entender o currículo, a identidade do profissional docente e a cultura escolar sob um novo paradigma. As autoras lembram que "o comportamento dos professores é motivado por um complexo conjunto de representações que envolvem valores, interesses, ideologias e questões da estrutura escolar" (2002, p. 323).

Tais crenças são resistentes a mudanças e atuam como lentes através das quais os professores percebem novas informações durante seu processo formativo e no decorrer de sua prática docente (VIEIRAABRAHÃO, 2004, p. 131). Em última instância, necessitam vivenciar situações de aprendizagem que têm base em outras perspectivas que a de "um modelo unívoco de ensino" (CASTRO, 2006, p. 319).

Dentro dessa perspectiva, este trabalho tem por objetivo discutir o processo reflexivo de duas professoras de inglês (uma pré-serviço e outra em serviço) acerca do desenvolvimento de sua prática pedagógica na escola pública. Tal investigação está inscrita em uma proposta de intervenção colaborativa na medida em que, como perspectiva teóricometodológica, permite construir um espaço de reflexão, de crítica e de negociação sobre as práticas discursivas desenvolvidas em sala de aula, bem como sua relação com os objetivos previamente definidos pelos atores sociais, nesse caso, as professoras pré-serviço e em serviço (MAGALHÃES; FIDALGO, 2008, p. 114; MAGALHÃES, 2002, p. 48).

\section{REVISÃO DA LITERATURA}

Para fazermos a análise e interpretação do discurso das participantes, utilizamos como aporte teórico a Análise Crítica do Discurso (ACD) (FAIRCLOUGH, 2003, 1989). A ACD tem demonstrado a preocupação em fazer a mediação entre o social e o linguístico, lançando mão, se necessário, de diferentes disciplinas e operacionalizando, assim, uma proposta transdisciplinar (CHOULIARAKI; FAIRCLOUGH, 1999, p. 16). Nesse sentido, por meio da concepção tridimensional de Fairclough (2001), procuramos focalizar o discurso, considerando três aspectos: a) o discurso enquanto texto, no qual são explicitadas as micro e macroestruturas da linguagem (o léxico, a gramática, a coesão e a estrutura textual) (2001., p. 103); b) o 
discurso enquanto prática discursiva, que discute os processos de produção, distribuição e consumo do texto, levando em consideração que a natureza desses processos varia de acordo com fatores sociais com os quais estão relacionados (2001, p. 106-107) e c) o discurso enquanto prática social, que envolve questões referentes à ideologia e ao poder a ele subjacentes (2001, p. 116).

No Brasil, a ACD vem sendo associada à Linguística SistêmicoFuncional (LSF), teoria proposta inicialmente por Halliday e colaboradores na década de 60 , com o objetivo de problematizar o caráter constituidor/estruturador da linguagem na atividade social, nas relações interpessoais e nos papéis sociais em contextos situacionais e culturais específicos (MOTTA-ROTH, 2006, p. 1). Nos últimos 40 anos, inúmeros pesquisadores (CHRISTIE, 2004; HALLIDAY, 1994; MARTIN, 1999; entre outros) colocaram novos olhares sobre ela, dos quais diferentes propostas e perspectivas emergiram. Particularidades à parte, há um consenso em torno do fato de que a LSF envolve uma teoria sobre a natureza da vida social, uma teoria da linguagem como um sistema semiótico fundamental na construção da vida social, e uma teoria acerca das possibilidades de mudança social (CHRISTIE, 2004, p. 21).

A discussão proposta por Halliday acerca do caráter funcional da linguagem serve de fio condutor para o desenvolvimento de uma teoria da linguagem na qual o gênero tem papel central. Halliday (1989, p. 3-4) procura explorar o papel sociossemiótico desempenhado pela linguagem na construção da vida social. Em outras palavras, argumenta que a linguagem conecta o texto ao contexto imediato no qual foi produzido. Isso significa dizer que ao estudarmos um texto em particular, estamos necessariamente debruçados sobre o contexto de situação no qual ocorreu. Desse modo, o texto toma a forma de uma unidade funcional e é, ao mesmo tempo, produto, já que podemos estudá-lo, e processo, uma vez que o estamos continuamente construindo ao fazermos nossas escolhas semânticas (1989, p. 11).

Além disso, a pesquisa sobre gêneros textuais tem procurado contribuir para a construção de teorias que possam dar conta da complexidade que é a atividade humana mediada pela linguagem (CRISTOVÃO; NASCIMENTO, 2005; MEURER; MOTTA-ROTH, 2002; por exemplo). Para exemplificar tal complexidade, Motta-Roth (2006, p. 1) lembra que qualquer exemplar de gênero textual reúne 
combinadamente elementos linguísticos de diferentes naturezas: fonológicos, morfológicos, lexicais, sintáticos, oracionais, semânticos, pragmáticos, discursivos e ideológicos. Esses se constituem na linguagem e organizam o conhecimento que construímos ao longo de experiências socialmente compartilhadas em contextos recorrentes (MOTTA-ROTH, 2005, p. 181).

$\mathrm{E}$, mais do que isso, os gêneros, quando associados a contextos sociais específicos, podem reforçar, reproduzir ou desafiar relações sociais, identidades e formas de representarmos a realidade (MEURER, 2002, p. 28). Uma pedagogia que busque descrever e explicar os gêneros textuais levando em consideração essas questões "poderá servir para evidenciar que, no discurso e através dele, os indivíduos produzem, reproduzem, ou desafiam as estruturas e as práticas sociais onde se inserem" (2002, p. 28).

Nesse sentido, adotamos essa perspectiva na medida em que as participantes, ao enfocarem o gênero pedagogicamente em sala de aula, procuravam explicitar as escolhas lexicogramaticais feitas pelos alunos ao usarem a língua em um determinado contexto. O exercício de análise dessas escolhas, que são feitas em um dado contexto sócio-histórico, possibilita o desvelamento das relações sociais - e de poder - que constituem as práticas sociais nas quais são feitas. $O$ processo de desnaturalização dessas escolhas - e das práticas sociais - contribuiu para o desenvolvimento de uma metaconsciência acerca de quem são, do que fazem e por que o fazem dessa ou daquela maneira. Em termos pedagógicos, tal perspectiva ofereceu subsídios sociais e linguísticos para que as participantes pudessem compreender e questionar a atividade social desenvolvida no contexto escolar.

\section{METODOLOGIA}

\subsection{As participantes}

Neste estudo, analisamos as reflexões de duas professoras de inglês: uma pré-serviço, Pâmela, e uma em serviço, Dóris, acerca de suas ações em sala de aula, no decorrer de 2007, em uma escola pública de Santa Maria. A seleção das participantes obedeceu a um critério de 
oportunidade e conveniência, que Patton (1986) chama de purposeful sample (amostra intencional). Isto porque Pâmela iniciava seu estágio curricular em uma escola estadual de ensino fundamental e médio da rede pública (doravante EPF). Ao ser encaminhada para a EPF, para o estágio curricular, conheceu Dóris.

Dóris formou-se em Letras - Português/Inglês em 1986, em uma universidade particular de Santa Maria. Nesses 21 anos de atividades, já lecionou inglês, português e literatura brasileira para todas as séries do ensino médio e fundamental que exigem essas disciplinas. Em 2007, durante a coleta de dados, a professora trabalhava com inglês na EPF e em uma escola municipal, e com português em outra escola municipal, nas quais cumpria uma carga horária de 50 horas semanais.

\subsection{Coleta de dados}

A coleta de dados foi realizada por meio de sessões de visionamento (reflexões acerca das ações em sala de aula) e da escritura de diários reflexivos (ver Quadro 1).

\subsection{Critérios de análise}

O discurso das participantes, em outras palavras, suas representações sobre a prática pedagógica desenvolvida durante o estágio curricular, coletado individualmente, foi analisado a partir de cinco critérios:

a) Manutenção da ordem cronológica: a cronologia ofereceu uma leitura que acompanhasse o próprio processo reflexivo vivenciado pelas participantes ao longo dos oito meses de atividades na escola EPF.

b) Identificação da temática central: a temática central - a linguagem como prática social - emergiu do texto das participantes ao avaliarem reflexivamente a aula ministrada. 


\begin{tabular}{|c|c|c|c|}
\hline Procedimentos & Perguntas norteadoras & $\begin{array}{l}\text { Fontes } \\
\text { de coleta } \\
\text { de dados }\end{array}$ & $\begin{array}{l}\text { Período de } \\
\text { coleta e número } \\
\text { de encontros }\end{array}$ \\
\hline $\begin{array}{l}\text { Visionamento } \\
\text { (reflexões acerca } \\
\text { das ações em } \\
\text { sala de aula) }\end{array}$ & $\begin{array}{l}\text { 1) Descrever: breve narrativa/relato da aula dada } \\
\text { - Qual o assunto da aula? } \\
\text { - Como tu descreverias os diferentes momentos da aula? } \\
\text { - Como ocorreu a apresentação do conteúdo? } \\
\text { - Em que medida os alunos participaram das atividades? } \\
\text { - Como tu trabalhaste as respostas dadas pelos alunos? } \\
\text { - Como os alunos atuaram durante as atividades propostas? } \\
\text { 2) Informar: o significado das ações } \\
\text { - Qual é o objetivo das atividades? } \\
\text { - Qual o conhecimento trabalhado nessas atividades? Por quê? } \\
\text { - Qual foi o teu papel nessas atividades? } \\
\text { - Qual foi o papel dos alunos nessas atividades? } \\
\text { - Qual a visão de ensino-aprendizagem que tu relacionas à tua aula? Por quê? } \\
\text { 3) Confrontar: o contexto histórico } \\
\text { - Como essa aula contribuiu para a formação de teu aluno? } \\
\text { - De que modo o tipo de conhecimento e de interação usado propiciou o } \\
\text { desenvolvimento da identidade de teu aluno? } \\
\text { - Que visão de indivíduo/sociedade essa forma de trabalhar ajudou a construir? } \\
\text { - Como a tua aula colaborou para a construção de cidadãos atuantes na sociedade em } \\
\text { que vivemos? } \\
\text { - Que interesses a tua forma de trabalhar ou o conteúdo abordado privilegiam? } \\
\text { 4) Reconstruir (Repensar a prática) } \\
\text { - Tu apresentarias as atividades da mesma maneira? Por quê? } \\
\text { - Que mudanças tu incorporarias à aula dada? Por quê? } \\
\text { - Que outra postura/papéis tu adotarias na aula/atividade? Por quê? }\end{array}$ & $\begin{array}{l}\text { Gravações } \\
\text { em áudio }\end{array}$ & $\begin{array}{l}\text { Período de } \\
\text { coleta do corpus: } \\
\text { Maio/dez } 2007 \\
29 \\
\text { encontros } \\
\text { Encontros } \\
\text { Semanais: } \\
\text { 2h30min/ } \\
\text { encontro }\end{array}$ \\
\hline
\end{tabular}




\begin{tabular}{|c|c|c|}
\hline $\begin{array}{l}\text { Escritura } \\
\text { de diários } \\
\text { (Reflexões sobre } \\
\text { a ação e as } \\
\text { leituras teóricas) }\end{array}$ & $\begin{array}{l}\text { 1. Como tu descreverias a tua aula? } \\
\text { 2. Qual era o objetivo das atividades realizadas? } \\
\text { 3. Quais foram os pontos "altos" e "baixos" da aula? Que atividades funcionaram } \\
\text { melhor e por quê? } \\
\text { 4. Como tu avalias a participação e a resposta dos alunos à aula dada? A que tu atribuis } \\
\text { tal participação? } \\
\text { 5. Como tu avalias o teu desempenho e o teu papel no processo de condução da aula? } \\
\text { 6. O que te levou a fazer essas escolhas, seguir esse caminho? } \\
\text { 7. Tu farias alguma mudança nas atividades ou na forma como elas foram ministradas? } \\
\text { Quais e por quê? } \\
\text { 8. Tu farias alguma mudança na tua atuação em sala de aula? }\end{array}$ & $\begin{array}{l}\text { Diários } \\
\text { reflexivos }\end{array}$ \\
\hline
\end{tabular}

Quadro 1 - Procedimentos, perguntas norteadoras e fontes de coleta de dados

\begin{tabular}{|l|l|l|l|l|}
\hline Critérios & 1) Descrever & 2) Informar & 3) Confrontar & 4) Reconstruir \\
\hline Conteúdo temático & $\begin{array}{l}\text { Contexto, temas trabalhados e } \\
\text { objetivo da aula. }\end{array}$ & $\begin{array}{l}\text { Teorias de ensinar e } \\
\text { aprender. }\end{array}$ & $\begin{array}{l}\text { Relação entre as ações e o } \\
\text { contexto sócio-histórico. }\end{array}$ & $\begin{array}{l}\text { Novas formas de } \\
\text { reconstrução da experiência. }\end{array}$ \\
\hline Exponentes linguísticos & $\begin{array}{l}\text { Relatos e descrições } \\
\text { seqüenciadas de ações. }\end{array}$ & $\begin{array}{l}\text { Explicações e definições } \\
\text { de conceitos que } \\
\text { subjazem às ações. }\end{array}$ & $\begin{array}{l}\text { Avaliações das ações, } \\
\text { papéis sociais, relevância e } \\
\text { pertinência do agir em no } \\
\text { enquadre sócio-histórico. }\end{array}$ & $\begin{array}{l}\text { Projeções de novas propostas } \\
\text { de encaminhamento de } \\
\text { ações. }\end{array}$ \\
\hline
\end{tabular}

Quadro 2 - Critérios utilizados para identificar, no corpus, os quatro estágios reflexivos (com base em LIBERALI, 2003, p. 122-124). 
c) Identificação dos processos reflexivos: os processos que nortearam a coleta de dados foram: 1) Descrever, 2) Informar, 3) Confrontar e 4) Reconstruir (SMYTH, 1992). Tais estágios permitiram às participantes refletir acerca dos múltiplos significados construídos por elas e projetar possíveis transformações nas práticas pedagógicas e nos contextos investigados.

Para fazer a identificação desses estágios, procuramos focalizar o conteúdo temático e os exponentes linguísticos típicos de cada processo reflexivo, com base em Liberali (2003, p. 122-124) (ver Quadro 2).

Nesta etapa da análise, as participantes foram identificadas pelo nome fictício, seguido da etapa de reflexão (Descrever - D; Informar - I; Confrontar - C e Reconstruir - R) e da data na qual a reflexão foi feita (Exemplo: Pâmela I\#10.06 - Excerto de Pâmela referente à etapa Informar, realizada no dia 10 de junho).

d) Seleção final das sessões reflexivas: as sessões foram selecionadas com o objetivo de explicitar o processo de reconfiguração das ações em sala de aula. Foram selecionadas as três sessões mais representativas do processo de reconfiguração da prática pedagógica.

e) Análise final: a análise, por meio da Análise Crítica do Discurso (FAIRCLOUGH, 2003, 1989) das participantes, procurou identificar em que medida suas ações em sala de aula incorporaram a perspectiva de aprendizagem sociocultural (VYGOTSKY, 2001).

Assim, as quatro categorias de análise mais recorrentes, que emergiram dos dados, foram: 1) Entendimento da linguagem apreendida na escola como parte da vida social; 2) Reconhecimento de que a instrução/ensino ajuda o aluno a percorrer a Zona de Desenvolvimento Proximal (ZPD) (VYGOTSKY, 2001); 3) Conscientização acerca da importância de explorar as escolhas lexicogramaticais feitas pelo aluno ao utilizar a linguagem; 4) Metaconscientização acerca da reconfiguração de sua prática pedagógica. 


\section{DISCUSSÃO DOS RESULTADOS: AS REFLEXÕES ACERCA DA PRÁTICA PEDAGÓGICA}

Nesta seção, analisamos as reflexões elaboradas pelas duas participantes desta pesquisa: Pâmela (Seção 4.1) e Dóris (Seção 4.2). Essas reflexões discutem o modo como (re)significam e representam discursivamente seu fazer pedagógico.

\subsection{A (re)significação e a representação do fazer pedagógico no discurso de Pâmela}

Pâmela realizou sua prática pedagógica na EPF com uma turma de 14 alunos de $\sigma^{\text {a }}$ Série. No início do processo reflexivo, ela traz para o consciente as crenças do que seja ensinar e aprender construídas ao longo de sua vivência escolar. As reflexões ajudam-na igualmente a questionar tais crenças e a pensar novas possibilidades de ação pedagógica em sala de aula a partir de uma perspectiva sociocultural.

$\mathrm{Na}$ primeira aula analisada, as reflexões de Pâmela acerca de sua prática pedagógica contribuem para que revise e reconfigure suas percepções acerca do trabalho com base em um texto em sala de aula, muito provavelmente construídas ao longo de sua experiência como aluna na escola (D\#02.07).

Pâmela D\#02.07: [...] Eu levei um texto como exemplo sobre os gaúchos, que falava assim, né, como que era a vida dos gaúchos, das roupas, o porquê daquelas roupas [...] Em seguida apliquei umas atividades em relação ao texto.

Pâmela avalia positivamente a escolha do texto, porque este explorava informações que fazem parte do conhecimento prévio dos alunos acerca dos gaúchos. Todavia, no processo de Informar, seu discurso já apresenta indícios de que a atividade havia ficado aquém das suas expectativas. 
Pâmela I\#02.07: [...] A aula desse dia não foi muito bem programada, [...] eu não estava me sentido muito bem preparada para trabalhar com um texto e acabei cometendo alguns erros. Não explorei muito as figuras e traduzi o texto oralmente, sendo que eu poderia ter trabalhado de outra forma, ter chamado a atenção deles para os cognatos, mas por falta de preparo, não fiz desse jeito [...] Eu confesso também que eu não pensei muito antes. [...] eu achei que ia ser fácil assim... Ah, beleza, pega um textinho e faz umas perguntinhas e tal. Quando chegou lá na frente que eu parei assim, sabe, eu pensei: e agora? Que que eu faço?

Pâmela (I\#02.07) procura entender o porquê de sua insatisfação com a atividade, revelando suas crenças em relação ao trabalho pedagógico com textos em sala de aula. Inicialmente, admite não se sentir preparada para fazê-lo e, por essa razão, teria adotado o procedimento apreendido ao longo de sua vivência escolar: a tradução. Prabhu (1990) lembra que a concepção de ensinar do professor pode ter diferentes origens, entre elas, suas experiências como aprendiz, incluindo as interpretações dos procedimentos de seus professores e a influência destes em sua aprendizagem.

Pâmela avalia negativamente ("acabei cometendo alguns erros", C\#02.07) o procedimento de tradução e, embora reconheça a existência de outras estratégias de leitura possíveis (exploração do texto não verbal, cognatos), que remetem à sua vivência acadêmica e às discussões realizadas pelo/no grupo focal, ainda não se sente preparada para utilizálas. Todavia, a externalização de suas crenças ajuda-a a trazer para o consciente suas escolhas pedagógicas (CRISTOVÃO, 2002, p. 140), bem como o conflito de vozes - e currículos - que permeia seu discurso (ROCHA; FREIRE, 2006).

Pâmela (C\#02.07) igualmente avalia o papel dos alunos naquela aula. Percebe que também os alunos assumem uma atitude de estranhamento em relação ao trabalho com o texto e acredita que eles esperam que o professor promova atividades que não demandem deles maiores esforços. Sua prática confirma, portanto, a crença de que os alunos se envolvem superficialmente com as atividades pedagógicas em 
sala de aula, identificada também em outras pesquisas (PETRECHE, 2006, por exemplo).

Pâmela C\#02.07: [...] eles não queriam trabalhar com texto ou talvez porque eles não estejam acostumados a trabalha com texto, sabe? [...] Então, não ficavam quietos, prestando atenção no que eu falava. Nas perguntas, eu até não digo que eles não sabiam o que que diziam as perguntas, sabe, é preguiça de pensar um pouquinho, de pensar e entender o que que as perguntas diziam.

Ao Reconstruir, Pâmela (R\#02.07) enumera novas possibilidades de trabalho com o texto que sua própria reflexão trouxe à tona. Tais estratégias revelam que propõe desconstruir o texto, explorando o assunto tratado e utilizando recursos verbais e não verbais. A reconstrução de suas representações acerca do que seja ensinar acontece, portanto, à medida que reflete sobre e verbaliza suas ações. Desse modo, revê e reorganiza os conhecimentos antigos, construindo novos modos de agir (VYGOTSKY, 2001, p. 183).

Pâmela R\#02.07: [...] eu acho que uma opção seria, quando eles encontrarem o site lá, olhar as palavras que eles conhecem, né, chama atenção pra isso. A partir delas, das fotinhos, se tem, do que que tá falando. $\underline{\text { O que tá explorando o texto? }}$.

Em setembro, Pâmela chama a atenção para a "testagem" ("uma tentativa de ver se eles iam melhorar") que encaminhou com os alunos. Ela havia feito uma primeira pesquisa sobre o país de escolha dos alunos e, posteriormente, ao propor a escritura de um texto acerca das informações coletadas, percebeu que eles estavam fazendo uma cópia ao invés de construir um texto próprio. Por essa razão, organizou, com o grupo focal, uma atividade na qual analisou as escolhas lexicogramaticais do autor de modo a explicitar para os alunos o processo de construção do texto (D\#10.09). 
Pâmela D\#10.09: Uma tentativa de ver se eles iam melhorar depois da atividade da Venezuela, se iam surgir resultados [...] foi bem tranquilo assim, bem melhor que a outra que a gente tinha feito [...] aproveitei para chamar a atenção deles pros verbos de novo e para a estrutura do texto [...].

O discurso de Pâmela permite antever que, assim como os alunos, ela também percorre o caminho da ZDP (VYGOTSKY, 2001, p. 254), na medida em que testa algumas "hipóteses" - as atividades preparadas com a ajuda do grupo focal - e, nesse processo, fortalece suas percepções/teorias acerca da condução da sua prática pedagógica. Vygotsky (2001, p. 254) afirma que o desenvolvimento dos conceitos espontâneos começa na esfera do concreto e do empírico e se move em direção às propriedades superiores: o caráter consciente e a voluntariedade. Pâmela (I\#10.09) percebe que a recorrência desses exercícios garante ao aluno - e a si mesma - um aumento gradual da autoconfiança, da segurança na realização da atividade.

Pâmela I\#10.09: Parece que eles entenderam mais assim a proposta, que não era pra copiar simplesmente só do texto, mas que era pra escrever com as palavras deles, né? Não sei se foi também mais fácil pra eles, mas pra mim pareceu bem mais fácil do que [...] na primeira vez [...] eu tentava passar as instruções assim bem claras pra eles. O que que não era pra fazer e o que era pra fazer, que também não precisava centrar só no texto, $[$ [... $\underline{\mathrm{E}}$ por ser a segunda vez que estavam fazendo, os alunos se sentiram mais seguros. Acho que foi muito importante termos feito essa atividade novamente [...].a gente já notou a diferença, eles já foram mais centrados, parece que já entendiam [...]

Ao avaliar seu desempenho e o processo desenvolvido, Pâmela destaca duas questões (C\#10.09). A primeira refere-se ao letramento digital possibilitado aos alunos: eles aprenderam a pesquisar na internet $\mathrm{e}$ criar um arquivo do Word, por exemplo. Nesse sentido, vivenciam novas práticas sociais e novas formas de comportamento no ambiente virtual (MOTTA-ROTH, 2003, p. 484). 
A segunda questão refere-se ao desenvolvimento de uma metaconsciência acerca do seu próprio processo de aprendizagem como professora no contexto de sala de aula, sendo capaz de relatar objetivamente os passos dados com os alunos, identificando as mudanças de procedimento na sua prática e os resultados dessas mudanças em si e nos alunos.

Pâmela C\#10.09: [...] Eles já sabiam copiar, colar, alguns lembravam como mandar para o e-mail [da professora] e isso foi muito importante para eles. Eles também já tinham em mente o que pesquisar mais especificamente. Então, tudo foi melhor. Mas foi bom pra mim também, porque por exemplo naquela turma que eu fui da Dóris, que eu ajudei um grupo, eu ajudei totalmente diferente do que antes [...] eu não tava mais perdida, eles falavam uma coisa e eu dizia coloca isso, não, como é que eu quero falar isso, vamos falar em português, aí eles falavam a frase e eu: 'tá, vamos lá agora', aí eu escrevia e eles escreviam um monte, aí depois e eu 'tá, agora vamos ler o que a gente escreveu', aí eles leram todo aquele texto [...] escrito em inglês [...] sabiam todas palavras, tudo.

Ao final da reflexão, Pâmela avalia que as escolhas feitas por ela e pelo grupo focal - de, em um primeiro momento, pesquisar diferentes países, resultou em um número maior de variáveis a serem trabalhadas em sala de aula: diferentes culturas e produção inicial de diferentes textos pelos alunos. Nesse sentido, destaca a possibilidade de pesquisar, em um primeiro momento, apenas um país e construir, em conjunto com os alunos, um primeiro texto acerca desse país (R\#10.09).

Pâmela R\#10.09: Trabalhar um texto. Um país [...] Então, [...] poderia ter construído junto um texto $[. .$.$] no quadro.$

Em novembro, Pâmela já havia começado o trabalho com o gênero textual "tira". Entre as atividades planejadas, estavam os exercícios de desconstrução dos contextos de situação e cultura das "tiras" escolhidas, realizados em sala de aula, e uma oficina de produção 
de tiras com o cartunista santa-mariense Byrata, que reuniu cerca de 80 alunos das disciplinas de português, espanhol e inglês no salão da EPF. De volta à sala de aula, Pâmela (D\#05.11) descreve a atividade de produção de uma versão em inglês da "tira" realizada na oficina.

Pâmela D\#05.11: [...] nessa aula, então, a gente ia construir as tiras deles em inglês $[\ldots .$.$] todo mundo já começou a desenhar e$ teve várias pessoas que mudaram [a tira inicial], resolveram fazer outras.

Novamente, informa (I\#0511), com clareza, passo a passo, como encaminhou o trabalho com os alunos, ajudando-os na produção individual do texto das tiras. É interessante perceber como, colaborativamente, contribui para a produção do texto, buscando o conhecimento prévio dos alunos acerca do vocabulário ("Como é que é tal palavra?") já visto, por meio de andaimes verticais (CAZDEN, 1983, apud MAGALHÃES, 1996, p. 5), e chamando a atenção para a organização estrutural das orações, dos conectores e das preposições ("tem uma palavrinha ali no meio, tem que ligar alguma coisa"). Embora alguns alunos tenham se mostrado inicialmente contrariados com a proposta da atividade, a expectativa de Pâmela de que a retomada da atividade em inglês entediaria os alunos (crença provavelmente construída por Pâmela nas suas experiências escolares) não se confirma, e a nova experiência em sala de aula contribui para que se questione.

Pâmela I\#05.11: [...] na parte de construir o texto ali assim [...] ajudamos eles com o que gostariam de escrever [...] não teve tantas dificuldades, sabe? Até eu ia dizendo assim: "Como é que é tal palavra?" [...] Falei tem uma palavrinha ali no meio, tem que ligar alguma coisa, que elas não sabiam, mas o principal ali assim eles sabiam [...] eu me surpreendi mesmo, achei que eles não iam querer fazer de novo, iam reclamar: [...] 'Ai, eu não sei desenhar', 'Eu não tenho idéias', 'Eu não sei o que fazer então eu não vou fazer, já decidi’. Aí a gente tinha que ir lá conversar, enfim....insistir um pouquinho. Mas depois assim fluiu normal.

TICKS - O desenvolvimento de uma metaconsciência... 
Pâmela argumenta que as atividades programadas sobre o gênero "tira", em especial a oficina, abriram caminho para o desenvolvimento de habilidades que, em princípio, não eram valorizadas pelos alunos, como desenhar (C\#05.11). Avalia, também, que a oficina possibilitou a participação dos alunos em novas práticas sociais ("uma coisa diferente") ou, como afirma Motta-Roth (2006, p. 5), trouxe o "mundo para a sala de aula", "levando o aluno a vivenciar o mundo "lá fora". Podemos perceber isso na análise dos adjetivos avaliativos ("maravilhoso, relevante, importante") utilizados por Pâmela, que destacam o grau de significação dado à atividade da oficina, ou, ainda, no uso de processos mentais afetivos ("motivou, adoraram") utilizados para apreciar o envolvimento dos alunos com a atividade.

Pâmela C\#05.11: foi algo assim do contexto deles, essa coisa de tiras, de quadrinhos pra quem gosta. Quem gosta de desenhar assim...sei lá...até os que não gostam de desenhar se empolgaram ali e saíram desenhando, foi muito legal. Foi uma motivação pra eles, uma coisa diferente que eles não costumam fazer nas aulas [...] eu acho que foi muito legal essa atividade [...] o fato do Byrata ter ido lá, foi maravilhoso, ajudou mais, motivou mais eles [...] acho que foi importante porque, que foi relevante, porque é algo que eles já tinham conhecimento, já tinham contato [...] algo que eles se identificaram, a temática das tiras [...] No final do ano, todos farão parte de um livro [...] Eles adoraram.

Pâmela argumenta que, antes do trabalho no grupo focal, idealizava sua prática pedagógica com base no ensino da gramática, pois esta representava o conhecimento apreendido até então. A partir das discussões no grupo focal, projeta novas prioridades: o ensino da língua para o uso, desvelando valores subjacentes e desenvolvendo uma metaconsciência no aluno para a não aceitação gratuita dos valores (im)postos socialmente. Em outras palavras, ensinar os alunos a "conviver com o diferente sem, obviamente, se considerar superior ou inferior a ele ou a ela, como gente" (FREIRE, 2003, p. 194). 
Pâmela R\#05.11: são as atividades típicas que a gente encontra nas escolas [...] eu planejei aquelas atividades baseadas no meu conhecimento, como eu já tinha tido as aulas daquele jeito, [...] eu acabei fazendo daquele jeito...e agora não, até por causa de todas as discussões que a gente teve e a preocupação em buscar atividades que fizessem parte do contexto deles, fossem mais voltadas pro uso da língua, também não só focadas na gramática. Eu acho que tudo isso assim mudou. Acho que é importante ensinar pra eles desde o começo [a] não ter preconceitos, aceitar as diferenças, pra saber se comportar, saber viver no mundo de hoje $[\ldots]$

As reflexões realizadas por Pâmela possibilitam-lhe ampliar as fronteiras dos conceitos de ensinar e aprender, construídas ao longo de sua trajetória escolar (ALONSO; FOGAÇA, 2007, p. 29), desenvolvendo uma metaconsciência acerca dessa transformação (Categoria 4, Quadro 3). No início de sua prática pedagógica, organiza as atividades a partir de um paradigma behaviorista, focalizando o ensino de elementos isolados da língua, particularmente o vocabulário. À medida que reflete sobre suas ações, traz para o consciente tais escolhas e reconfigura o papel do ensino, da instrução em sala de aula (Categoria 2, Quadro 3).

No início do processo, Pâmela já é capaz de verbalizar algumas características da perspectiva sociocultural, como no trabalho com o texto em sala de aula, mas ainda não se sente segura para colocá-las em prática. À medida que reflete acerca desse paradigma e de sua prática, percebe a importância de explorar as escolhas lexicogramaticais dos alunos ao utilizarem a linguagem (Categoria 3, Quadro 3), construindo novas formas de agir e valorizando o ensino da língua como ferramenta para ação no mundo (Categoria 1, Quadro 3). 


\begin{tabular}{|l|l|}
\hline $\begin{array}{l}\text { Categorias } \\
\text { de análise }\end{array}$ & Pâmela \\
\hline $\begin{array}{l}\text { 1) Entendimento da } \\
\text { linguagem apreendida na } \\
\text { escola como parte da } \\
\text { vida social }\end{array}$ & $\begin{array}{l}\text { A gente teve e a preocupação em buscar atividades que } \\
\text { fizessem parte do contexto deles, fossem mais voltadas pro } \\
\text { uso da língua, também não só focadas na gramática. Acho } \\
\text { que é importante ensinar pra eles desde o começo [a] não ter } \\
\text { preconceitos, aceitar as diferenças, pra saber se comportar, } \\
\text { saber viver no mundo de hoje. }\end{array}$ \\
\hline $\begin{array}{l}\text { 2) Reconhecimento de } \\
\text { que a instrução/ensino } \\
\text { ajuda o aluno a percorrer } \\
\text { a ZPD }\end{array}$ & $\begin{array}{l}\text { Eu tentava passar as instruções assim bem claras pra eles. O } \\
\text { que não era pra fazer e o que era pra fazer, que também não } \\
\text { precisava centrar só no texto [...] E por ser a segunda vez } \\
\text { que estavam fazendo, os alunos se sentiram mais seguros. } \\
\text { Acho que foi muito importante termos feito essa atividade } \\
\text { novamente [...].a gente já notou a diferença, eles já foram } \\
\text { mais centrados, parece que já entendiam. }\end{array}$ \\
\hline $\begin{array}{l}\text { 3) Conscientização acerca } \\
\text { da importância de } \\
\text { explorar as escolhas } \\
\text { léxico-gramaticais feitas } \\
\text { pelo aluno ao utilizar a } \\
\text { linguagem. }\end{array}$ & $\begin{array}{l}\text { A gente foi pro laboratório, pra fazer de novo a pesquisa } \\
\text { sobre os países que eles escolhessem. Aproveitei para } \\
\text { chamar a atenção deles pros verbos de novo e para a } \\
\text { estrutura do texto. }\end{array}$ \\
\hline $\begin{array}{l}\text { Q) Metaconscientização } \\
\text { acerca da reconfiguração } \\
\text { de sua prática pedagógica }\end{array}$ & $\begin{array}{l}\text { Eu planejei aquelas atividades baseadas no meu } \\
\text { conhecimento, como eu já tinha tido as aulas daquele jeito, } \\
\text { co.. eu acabei fazendo daquele jeito...e agora não, até por } \\
\text { causa de todas as discusões que a gente teve e a } \\
\text { preocupação em buscar atividades que fizessem parte do } \\
\text { contexto deles, fossem mais voltadas pro uso da língua, } \\
\text { também não só focadas na gramática. Eu acho que tudo isso } \\
\text { assim mudou. Acho que é importante ensinar pra eles desde } \\
\text { o começo [a] não ter preconceitos, aceitar as diferenças, pra } \\
\text { saber se comportar, saber viver no mundo de hoje. }\end{array}$ \\
\hline
\end{tabular}

\subsection{A (re)significação e a representação do fazer pedagógico no discurso de Dóris}

Inicialmente, Dóris centra suas atenções no ensino de elementos lexicogramaticais isolados e, paulatinamente, descobre as possibilidades de ampliar as fronteiras dessa perspectiva, explorando a linguagem como atividade socialmente situada. Essa reconfiguração tem início no 
momento em que reconhece que suas ações em sala de aula "não atendem as expectativas da gurizada". Essa insatisfação identificada nos alunos a levou a experimentar novas possibilidades de ação em sala de aula (GIMENEZ; ARRUDA; LUVUZARI, 2004), que resultam na reconfiguração dos papéis do aluno no processo de ensino e aprendizagem.

Em setembro, discutiu com a turma um texto que explora aspectos culturais da Venezuela (D\#03.09). A atividade procurou salientar de que maneira os elementos lexicogramaticais constroem o sentido no texto, perspectiva que não fazia parte de sua rotina de trabalho ("eu nunca tinha explorado dessa maneira"), embora o enfoque sobre elementos isolados da língua seja exaustivo na escola ("se trabalha, trabalha, trabalha...”) (I\#03.09).

Dóris D\#03.09: [a leitura] foi o texto sobre [...] a Venezuela.

Dóris I\#03.09: eles conseguiram entender o texto de uma forma mais tranquila, sem tradução [...] esse foco no léxico-gramatical $[\ldots]$ em relação às coisas que foram retiradas do texto, [...] valorização dos sentidos de palavras e expressões. [...] relacionar os verbos às funções que exercem dentro do texto, com relação aos sentidos [...] essa parte semântica aqui eu nunca tinha explorado dessa maneira. Achei tão interessante [eles não tinham muito claro o que é um verbo] o verbo e o substantivo [...] quer dizer, no fim, é trabalhado, se trabalha, trabalha, trabalha...

Percebemos, ainda, uma segurança maior, materializada na circunstância ("de uma forma mais tranquila" - I\#03.09), lembrando que os sentimentos iniciais eram de angústia e medo em relação às atividades desenvolvidas com os alunos. Embora o trabalho com elementos gramaticais isolados tenha sempre feito parte de sua prática pedagógica, percebe que não apresenta a mesma significação para os alunos, pois acredita que eles desejam ser estimulados, desafiados pela escola (prerrogativa, segundo ela, não contemplada pelo paradigma tradicional). Nesse sentido, destaca a importância de o professor não subestimar sua capacidade cognitiva ou cercear suas habilidades comunicativas (C\#03.09).

TICKS - O desenvolvimento de uma metaconsciência... 
Dóris C\#03.09: [...] a forma como a gente vinha trabalhando, não é possível trabalhar com eles, porque eles se entediam [...] a metodologia empregada em sala de aula, de um modo geral, não atende mais as expectativas dessa gurizada [...] porque eles são muito rápidos eles captam e eles precisam de atividades, [...] desafios permanentes, e eles, as vezes tu pensa que eles não têm capacidade cognitiva pra ir além e eles têm, têm entendimento de relacionar coisas só que, às vezes, pelo tipo de aula que se prepara, não se consegue elaborar uma atividade que suscite isso $[\ldots]$

Dentro da perspectiva de ensino que começa a ser configurada por Dóris (R\#03.09), os alunos têm liberdade para se movimentarem dentro das atividades, explorando o texto e suas múltiplas significações por meio de diferentes estratégias de leitura. Nesse sentido, percebe ainda que, sob uma perspectiva de leitura crítica (WALLACE, 1992), os assuntos não ficam "estagnados".

Dóris R\#03.09: [...] esta sistemática parece que chama mais [a atenção do aluno], porque são várias atividades em cima de uma proposta de texto [...] e isto não tá estagnando com os assuntos né, e deixando eles se movimentarem mais dentro de uma temática ou de um texto, [...] se tornando interessante principalmente eles se sentindo bem em relação a compreensão, o quanto eles conseguem compreender através das coisas que são exploradas [...] gravura, pré-leitura, que são as atividades mais orais, daí quando eles entram na leitura, eles já conseguem perceber onde, conseguem localizar dentro do texto as informações que estão sendo solicitadas com muito mais facilidade.

Em setembro, Dóris iniciou o trabalho com as "tiras". Como o exemplar selecionado ("Tira da Mônica", do cartunista Maurício) tinha como temática a cultura punk, o grupo preparou uma atividade para discussão desse contexto no sentido de introduzir o assunto (D\#17.09). 
Dóris D\#17.09: Foi trabalhado um texto a partir de gravuras sobre os punks. Foram questionados outros grupos, como os emos, góticos e hippies.

Dóris acredita que a motivação dos alunos resulta da liberdade que recebem para o desenvolvimento de atividades instruídas, mas não cerceadas pelo professor ("juntos parece que eles participam melhor") (I\#17.09). Ao refletir sobre a atividade, utiliza diferentes adjetivos e advérbios avaliativos ("bem participadas... bem produtivas... bem interessante... bem melhor") para acentuar a participação dos alunos e os resultados positivos obtidos.

Dóris I\#17.09: [...] todas as atividades elas têm sido assim bem produtivas, e bem participadas [...] por eles, esse envolvimento que eu acho bem interessante [...] eles irem fazendo juntos parece que eles participam melhor do que deixando eles fazerem, por exemplo, assim largar a atividade agora vocês façam [...] bem melhor, é uma coisa assim que eu não tinha bem essa prática [...] de fazer a atividade junto com eles [...] cada questão [...] fazer com que eles refletissem bem, sobre a questão e elaborassem a sua própria resposta [...] aquele que é mais lento ele capta melhor com o raciocínio do mais rápido [...] porque o grupo é bem heterogêneo.

A instrução (I\#17.09) a que se refere agora é de natureza diferente daquela realizada por ela no início de seu processo reflexivo. Naquele momento, sua preocupação era oferecer ao aluno "estruturas présequenciadas e rígidas" da língua de modo que eles pudessem exercitá-las por meio da repetição. Nesse ponto, sua preocupação era acompanhar os alunos durante a discussão das atividades, subsidiando o processo reflexivo e a construção dos seus textos. Em outras palavras, acompanhá-los no seu deslocamento pela ZDP (VYGOTSKY, 2001, p. 254). Além disso, Dóris não se angustia mais com a heterogeneidade do grupo. Ao contrário, percebe que aquele aluno mais capaz pode assistir o desempenho do menos capaz (GALLIMORE; THARP, 1996, p. 180). 
Dóris (C\#17.09) destaca que a atividade desenvolvida sobre os punks foi além da descrição de suas características físicas típicas, ressaltando que o texto trabalhado discutia a origem sócio-histórica do movimento e as atividades problematizavam os julgamentos apressados em relação à cultura. Dóris avalia que o trabalho acabou contribuindo para a discussão, com os alunos, acerca da importância de evitar a criação de estereótipos daqueles indivíduos e grupos considerados "diferentes" pelo restante da sociedade. Freire (2003, p. 204) argumenta em favor da análise, em sala de aula, dos descompassos da democracia, já que "a tolerância não é favor que 'gente superior' faz à 'gente inferior' [...] é dever respeitar o direito de todos de serem diferentes [...]”, o que não nos obriga a concordar com eles (2003, p. 194).

Dóris C\#17.09: [...] que os punks surgiram na Inglaterra era um movimento, era uma reação ao sistema [político-econômico] da Inglaterra [...] eles sabiam [...] se eram hippies, punks, emos ou góticos [...] a diferença de cada um [...] características gerais [...] deu pra fazer um levantamento a respeito dessa questão de [...] preconceito, da discriminação em relação às pessoas que optam por serem diferentes [...] e eu achei bem interessante isso, porque, de uma certa forma, tu tá trabalhando essa questão do ser imparcial em relação a preconceito e discriminação [...] na verdade imparcial nunca é, $[\ldots]$ tentar não julgar 0 comportamento.

Desse modo, ao Reconstruir (R\#17.09), Dóris propõe, como atividade subsequente, desnaturalizar o argumento, subjacente ao discurso da "tira", de que os punks fazem parte do "túnel dos horrores" em um parque de diversão. Assim, abre espaço para uma leitura crítica do texto em direção à construção de uma perspectiva de respeito à diversidade social. Além disso, sua reflexão acerca do processo de desempenho assistido (GALLIMORE; THARP, 1996, p. 180), com base em sua própria prática em sala de aula, reafirma a estratégia de organizar o grupo de modo que aqueles mais capazes possam subsidiar os demais na realização da atividade. 
Dóris R\#17.09: [faltou trabalhar a última questão] a questão poderia ser se esse comentário é preconceituoso [...] ou não e por quê? e daí envolveria justamente essa questão assim do, do respeito à diversidade [...] e não foi falado [...] eu [...] pensei em mesclar, por exemplo, [...] porque ali o grupo do [nome do aluno] eles são extremamente rápidos [...] de raciocínio [e tem o outro] que é extremamente distraído [...] ele presta atenção em tudo e é aéreo $[. .$.

Após a realização da oficina de "tiras" com os alunos, o cartunista que ministrou a oficina (Byrata) retornou à escola para ajudá-los na finalização dos trabalhos para uma publicação (D\#05.11).

Dóris D\#05.11: [...] foram feitas as tiras [...] porque o Byrata viria [...] nessa segunda-feira agora, então, nós adiantamos as tiras [...]

Dóris (I\#05.11) conseguiu, em sua proposta de ensino, deslocar sua atenção da estrutura da língua para o processo de produção verbal e não verbal da "tira", em última instância, para a prática social (MEURER; MOTTA-ROTH, 2002, p. 11). Essa mudança de paradigma se reflete em sua instrução, na medida em que dá liberdade de criação aos alunos, desobrigando-os do uso de "estruturas-padrão" da língua. Para Dóris, essa nova perspectiva de trabalho valoriza a autoestima dos alunos e contribui para a construção de suas identidades ("eles se sentem em relação ao trabalho"), uma vez que concentra esforços no que os alunos são capazes de fazer ("tu estimula através do acerto"). Vygotsky (2001, p. 242) argumenta que a instrução deve focalizar justamente as funções psicológicas que ainda estão em processo de maturação no aluno.

Dóris I\#05.11: [...] não é uma estrutura-padrão que tu tá ensinando ali, mas a partir daquilo que eles querem criar, que eles querem dizer [...] eles estão manifestando o que eles sentem em relação ao trabalho [...] no momento que tu [...] valoriza tudo que ele faz [...] a gente não tá estimulando o erro, mas o acerto [...] eu vejo assim que o salto é quântico [...] em relação à produtividade 
[...] Porque daí todos se sentem capazes [de produzir] individualmente [...] acho que tá ligado à questão da autoestima.

Dóris (C\#05.11) problematiza as consequências, para o aluno e para si mesma, das mudanças vivenciadas em sala de aula. Vale lembrar que seu discurso não está mais carregado de elementos lexicogramaticais que denotam angústia, incerteza e insegurança, como ficava evidenciado no início do seu processo reflexivo. Percebe os alunos mais participativos e argumenta que tem procurado desnaturalizar alguns mitos, como o de que a aprendizagem da língua na escola é difícil, para não dizer impossível (COELHO, 2006). Além disso, salienta a importância de encaminhar uma instrução que ofereça liberdade de produção ao aprendiz, levando em consideração suas individualidades no processo de aprendizagem. Vygotsky (2001, p. 242) chama à atenção o fato de que mesmo as crianças, embora tenham a mesma idade, percorrem a ZDP de maneiras distintas.

Dóris C\#05.11: [...] essa forma de trabalhar, [...] construindo juntamente com eles, eu acho que fez com que eles se sentissem mais seguros e [...] sem medo de errar [...] tanto pra escrever quanto pra falar, quanto pra... até pra pensar [...] eu percebi [...] que todo o processo avaliativo foi um processo de construção [...] dar oportunidade $[\ldots]$ isso não significa que vai construir sozinho, [...] ele vai construir, ele vai tentar construir, na medida que ele sentir a dificuldade, ele vai pedir auxilio e ele vai construir ate onde ele acha que ele pode construir [...] quer dizer, não é barrado: "tu vai aprender até aqui, tu vai dizer até isso" [...] muitos iam além do que a gente esperava e outros, pouquinho $\underline{\text { menos }[\ldots]}$

Nesse processo de reconfiguração dos atores sociais em sala de aula, Dóris projeta novos papéis para os alunos mais capazes: de monitores, aproveitando suas habilidades colaborativamente, para auxiliar os demais no desenvolvimento das atividades. Pesquisas discutidas por Wigfield, Eccles e Rodriguez (1998, p. 91) relatam que crianças com altas habilidades se beneficiam do trabalho colaborativo, 
assumindo o papel de "líderes" e "professores", enquanto aquelas com habilidades menores se beneficiam da instrução proporcionada pelas primeiras.

Dóris R\#05.11: [...] eu acho que vou ter que retomar toda essa atividade na próxima aula, porque tem alunos que não fizeram [...] esses que já trabalharam poderiam trabalhar, junto com os que não trabalharam, como orientadores, pra eles não ficarem sem atividades naquele dia, porque se não vai ficar difícil agora trabalhar com uma metade e a outra metade faz outra coisa [...] daí eles vão ensinar $[. .$.

A caminhada reflexiva de Dóris culmina na conscientização acerca da natureza do paradigma tradicional de ensino, no qual estava inserida na escola, dando os primeiros passos em direção ao seu questionamento. Essa perspectiva se constitui pelo enfoque na tradução (PINHEL, 2004, p. 75) e em elementos formais da língua (WALLACE, 1992, p. 72-73). Ao exercitar novos modos de organizar o seu fazer em sala de aula, adotando estratégias de leitura e a exploração de gêneros textuais, como as "tiras", amplia as fronteiras dos seus conceitos de linguagem, ensino e aprendizagem e o ensino de elementos lexicogramaticais passa a ser uma instância da prática pedagógica (Categoria 3, Quadro 4). Valoriza a aprendizagem colaborativa e o papel da instrução (Categoria 2, Quadro 4); utiliza contextos outros de ensino, deslocados da sala de aula, como estratégia de motivação dos alunos; e ensina a linguagem por meio de atividades que explorem práticas sociais significativas para o aprendiz (Categoria 1, Quadro 4), desenvolvendo uma metaconsciência acerca da necessidade de evitar a padronização do conhecimento e do modo como ele é apreendido nesse processo (Categoria 4, Quadro 4). 


\begin{tabular}{|c|c|}
\hline $\begin{array}{l}\text { Categorias } \\
\text { de análise }\end{array}$ & Dóris \\
\hline $\begin{array}{l}\text { 1) Entendimento da } \\
\text { linguagem apreendida na } \\
\text { escola como parte da } \\
\text { vida social }\end{array}$ & $\begin{array}{l}\text { A partir desse trabalho teórico e prático em sala de aula, } \\
\text { proporcionou-se uma oficina com o cartunista Byrata. Essa } \\
\text { oficina integrou as disciplinas de português, espanhol, inglês } \\
\text { e ciências. [...] O trabalho já vinha sendo feito, preparado, } \\
\text { culminou nessa oficina com o Byrata. }\end{array}$ \\
\hline $\begin{array}{l}\text { 2) Reconhecimento de } \\
\text { que a instrução/ensino } \\
\text { ajuda o aluno a percorrer } \\
\text { a ZPD }\end{array}$ & $\begin{array}{l}\text { E eu tô tentando }[. . .] \text { passar o trabalho que está sendo feito } \\
{[\ldots . .] \text { numa turma de oitava série }[\ldots . .] \text { procurando sempre }} \\
\text { tentando fazer este estilo de pré-leitura }[. . .] \text { é uma coisa que } \\
\text { no trabalho já tá refletindo de forma diferente. }\end{array}$ \\
\hline $\begin{array}{l}\text { 3) Conscientização acerca } \\
\text { da importância de } \\
\text { explorar as escolhas } \\
\text { lexicogramaticais feitas } \\
\text { pelo aluno ao utilizar a } \\
\text { linguagem. }\end{array}$ & $\begin{array}{l}\text { Só que [...] é uma dificuldade, eles não conseguiram montar } \\
\text { os textos [...] Faltam elementos [léxico-gramaticais] pra } \\
\text { construção e elementos bem importantes. }\end{array}$ \\
\hline $\begin{array}{l}\text { 4) Metaconscientização } \\
\text { acerca da reconfiguração } \\
\text { de sua prática pedagógica }\end{array}$ & $\begin{array}{l}\text { como a gente, sem se dar conta, acaba [...] tolhendo o } \\
\text { potencial criativo [...] padroniza o comportamento, } \\
\text { padroniza, assim, a aquisição do próprio conhecimento } \\
{[\ldots] \text { Todos mais ou menos têm que chegar neste ponto aqui. }} \\
{[\ldots] \text { Tu nivela todos. Não adianta querer esconder. É isso aí }} \\
\text { que a gente faz. [o professor e a escola precisam] } \\
\text { proporcionar pro teu aluno a questão da música, ou a } \\
\text { questão da dança, ou do teatro, [...] em forma de oficinas, ou } \\
\text { em forma de escolhinha paralela, ou transformar a sala de } \\
\text { aula. }\end{array}$ \\
\hline
\end{tabular}

Quadro 4 - As escolhas lexicogramaticais de Dóris e as representações construídas na configuração de uma prática pedagógica que reposiciona o papel do aluno em sala de aula.

\section{CONSIDERAÇÕES FINAIS}

O processo reflexivo proposto nesta investigação permitiu às participantes refletirem acerca das concepções teóricas de aprendizagem construídas ao longo de sua formação escolar e universitária. No início do processo reflexivo, seu discurso indicava um alinhamento a uma concepção que tinha como enfoque o ensino de elementos gramaticais isolados. Essa perspectiva norteava, da mesma forma, suas ações em sala de aula, no início das atividades na escola pública. À medida que as 
reflexões teóricas e a prática pedagógica na escola pública avançam, suas concepções são reconfiguradas em direção a uma perspectiva de linguagem como prática social. Tal reconfiguração provoca mudanças nos papéis de professora e alunos no contexto de sala de aula. Assim, gradualmente assumem o papel de professora que, além de ser responsável por organizar o conhecimento a ser discutido em sala de aula e efetivamente dar conta do processo de instrução desse conhecimento (VYGOTSKY, 2001, p. 243), precisa desenvolver no aluno uma metaconsciência acerca de suas escolhas ao utilizar a linguagem (HALLIDAY, 1994, p. xxvi). Essa reconfiguração resulta em mudanças no papel do aluno que, de receptor de conhecimento, passa a ser ator social (FAIRCLOUGH, 2003, p. 145) em sala de aula, participando da escolha dos assuntos a serem discutidos e se posicionando frente ao conhecimento elaborado.

\section{REFERÊNCIAS}

ALONSO, T.; FOGAÇA, F. C. Crenças sobre o ensino de inglês na prática de ensino. In: GIMENEZ, T. (org.). Tecendo as manhãs: Pesquisa participativa e formação de professores de inglês. Londrina: UEL, 2007. p. 23-40.

CASTRO, S.T.R. Formação da competência do futuro professor de inglês. In: LEFFA, V. J. (Org.). O professor de línguas: construindo a profissão. 2 ed. Pelotas: EDUCAT, 2006. p. 307-321.

Teoria e prática no processo de reculturação de professores de inglês. In: CELANI, M. A. A. (Org.). Professores e formadores em mudança: Relato de um processo de reflexão e transformação da prática docente. São Paulo: Mercado de Letras, 2003. p. 69-78.

CELANI, M.A.A.; MAGALHÃES, M.C. Representações de professores de inglês como língua estrangeira sobre suas identidades profissionais: Uma proposta de reconstrução. In: MOITA LOPES, L. P.; BASTOS, L. C. (Orgs.). Identidades: recortes multi e interdisciplinares. Campinas, SP: Mercado de Letras, 2002. p. 319-337.

CHOULIARAKI, L.; FAIRCLOUGH, N. Discourse in late modernity: Rethinking critical discourse analysis. Edimburgh: Edinburgh University Press, 1999.

TICKS - O desenvolvimento de uma metaconsciência... 
CHRISTIE, F. Systemic functional linguistics and a theory of language education. Ilha do Desterro, v. 46, p. 13-40, jan./jun. 2004.

COELHO, H. S. H. "É possível aprender inglês na escola?" Crenças de professores sobre o ensino de inglês em escola públicas. In: BARCELOS, A. M. F.; VIEIRA ABRAHÃO, M. H. (Orgs.). Crenças e ensino de línguas: foco no professor, no aluno e na formação de professores. Campinas, São Paulo: Pontes, 2006. p. 125-143.

CRISTOVÃO, V.L.L. Modelo didático de gênero como instrumento para formação de professores. In: J. L. MEURER; D. MOTTA-ROTH (Orgs.). Gêneros textuais. São Paulo: EDUSC, 2002. p. 31-73.

CRISTOVÃO, V. L. L.; NASCIMENTO, E. L. Gêneros textuais e ensino: Contribuições do interacionismo sócio-discursivo. In: KARWOSKI, A. M.; GAYDECZKA, B. \& BRITO, K. S. (Orgs.). Gêneros textuais: reflexões e ensino. União da Vitória: Kaigangue, 2005. p. 35-60.

FAIRCLOUGH, N. Analysing discourse: textual analysis for social research. London/New York: Routledge, 2003.

Relato de um processo de reflexão e transformação da prática docente. Discurso e mudança social. Brasília: Editora UnB, 2001.

Language and power. London: Longman, 1989.

FREIRE, P. Cartas a Cristina: Reflexões sobre a minha vida e a minha praxis. Organização e notas Ana Maria Araújo Freire. 2 ed. rev. São Paulo: Editora Unesp, 2003.

GALLIMORE, R.; THARP, R. O pensamento educativo na sociedade: Ensino, escolarização e discurso escrito. In: MOLL, L. C. (Org.). Vygotsky e a educação: Implicações pedagógicas da psicologia sócio-histórica. Porto Alegre: Artes Médicas, 1996. p. 171-99.

GIMENEZ, T. (Org.). Tecendo as manhãs: Pesquisa participativa e formação de professores de inglês. Londrina: UEL, 2007.

. (Org.). Trajetórias na formação de professores de línguas.

Londrina: Editora UEL, 2002.

GIMENEZ, T; ARRUDA, N. I. L.; LUVUZARI, L. H. Procedimentos reflexivos na formação de professores: uma análise de propostas recentes. Intercâmbio, v. 13, p. 1-5, 2004.

HALLIDAY, M.A.K. An introduction to functional grammar. 2 ed. London: Edward Arnold, 1994. 
. Part A. In: HALLIDAY, M. A. K.; HASAN, R. Language, context

and text: Aspects of language in a social-semiotic perspective. Oxford: Oxford University, 1989. p. 3-49.

LIBERALI, F. O papel do multiplicador. In: CELANI, M. A. A. (Org.).

Professores e formadores em mudança: relato de um processo de reflexão e transformação da prática docente. São Paulo: Mercado de Letras, 2003. p. 119132.

MAGALHÃES, M. C. C. (Org.). A formação do professor como um profissional crítico: linguagem e reflexão. Campinas, SP: Mercado de Letras, 2004.

. O professor de línguas como pesquisador de sua ação: A pesquisa colaborativa. In: GIMENEZ, T. (Org.). Trajetórias na formação de professores de línguas. Londrina: Editora UEL, 2002. p. 39 -58.

. Contribuições da pesquisa sócio-histórica para a compreensão de contextos interacionais da sala de aula de línguas: Foco na formação de professores. The ESPecialist, v. 17, n. 1, p. 1-18, 1996.

MAGALHÃES, M. C.; FIDALGO, S. Teacher education language in collaborative and critical reflective contexts. In: VIEIRA-ABRAHÃO, M H. \& GIL, G. Educação de professores de línguas: Os desafios do formador. Campinas, SP: Pontes, 2008. p. 105-124.

MARTIN, J. Mentoring semogenesis: 'Genre based' literacy pedagogy. In: CHRISTIE, F. (Ed.). Pedagogy and shaping of consciousness: linguistics and social processes. London and New York: Continuum, 1999. p. 123-55.

MEURER, J. L. Uma dimensão crítica de estudos de gêneros textuais. In: J. L. MEURER; D. MOTTA-ROTH (Orgs.). Gêneros textuais. São Paulo: EDUSC, 2002. p. 17-29.

MEURER, J. L.; MOTTA-ROTH, D. (Orgs.). Gêneros textuais. São Paulo: EDUSC, 2002.

MOTTA-ROTH, D. O ensino de produção textual com base em atividades sociais e gêneros textuais. Linguagem em (Dis)curso, v. 6, n. 3, p. 1-14, 2006.

Being an e-fly on the wall, observing an EFL computer-mediated teacher. In: TOMITCH, L. M. B. et al. (Orgs.). A interculturalidade no ensino de inglês. Florianópolis: UFSC, 2005. p. 557-577.

TICKS - O desenvolvimento de uma metaconsciência... 
A dinâmica de produção de conhecimento: teoria e dados, pesquisador e pesquisados. Revista Brasileira de Lingüística Aplicada, Belo Horizonte, MG: UFMG, v. 3, n. 1, p. 165-177, 2003.

PATTON, M. Q. Qualitative evaluation methods. Beverly Hills, CA: Sage, 1986.

PETRECHE, C. R. C. Student's an teacher's beliefs and the lack of interest in English classes. In: GIMENEZ, T.; CRISTOVÃO, V. L. L. Teaching English in context: contextualizando o ensino de inglês. Londrina, UEL, 2006, p. 117130.

PINHEL, C. O. Reflexões sobre a leitura em aula de inglês como língua estrangeira em uma escola pública. In: CONSOLO, D. A.; VIEIRAABRAHÃO, M. H. Pesquisa em lingüística aplicada: ensino e aprendizagem de língua estrangeira. São Paulo: Editora Unesp, 2004, p. 55- 80.

PRABHU, N.S. There is no best method - Why? TESOL Quarterly, v. 24, n. 2, p. 161-176, 1990.

ROCHA, L. L.; FREIRE, A. M. F. O professor em formação e o conflito de currículos: Uma experiência de pesquisa-ação. In: LEFFA, V. J. (Org.). O professor de línguas: Construindo a profissão. 2. ed. Pelotas: EDUCAT, 2006. p. 295-306.

SMYTH, J. Teacher's work and the politics of reflection. American Educational Research Journal, v. 25, n. 2, p. 267-300, 1992.

VIEIRA-ABRAHÃO, M. H. Crenças, pressupostos e conhecimentos de alunosprofessores de língua estrangeira e sua formação inicial. In: VIEIRAABRAhÃO, M. H. (Org.). Prática de ensino de língua estrangeira: experiências e reflexões. Campinas: Pontes Editores, 2004. p. 131-52.

VYGOTSKY, L. S. Obras escogidas, tomo II. 2. ed. Madri: Visor, 2001.

WALLACE, C. Reading. New York: Oxford University Press, 1992.

WIGFIELD, A; ECCLES, J. S.; RODRIGUEZ, D. The development of children's motivation in school contexts. Review of Research in Education, v. 23, p. 73-118, 1998.

Recebido em 16/07/09. Aprovado em 24/08/10. 
Title: The development of a teacher's meta-awareness on the importance of experiencing language as social practice in an EFL classroom through collaborative research

Author: Luciane Kirchbof Ticks

Abstract: In this paper is discussed the thoughtful process experienced by two English teachers, as they problematize their procedures in the classroom. In the foreground is the process of reconfiguration of their pedagogical activities, which initially would focus on the isolated lexical-grammatical structures and which, along the reflective process, were reconfigured to focus more on textual genres and on the (de)construction of the situational and cultural contexts in which such texts are socially produced and experienced (MOTTA-ROTH, 2006). Such thoughts were developed by means of a collaborative research process (MAGALHAES, 2004). The discourse analysis of those teachers indicate that the reflective process allowed them to develop a meta-awareness about how language organizes itself and constitutes itself when it mediates the social activity.

Keywords: Collaborative Research. Critical Discourse Analysis. Language as Social Practice.

TICKS - O desenvolvimento de uma metaconsciência... 